\title{
Editorial
}

\section{Reflexiones en torno a los alcances y limitaciones de las estrategias de desarrollo económico local en El Salvador}

En 1999, el Fondo de Inversión Social para el Desarrollo Local (FISDL) conformó un Grupo Consultivo al cual se le encomendó la formulación de una "Estrategia Nacional de Desarrollo Local" (ENDL). Este grupo fue conformado por los siguientes actores del desarrollo local: COMURES, Red de ONG para el desarrollo local, FUSADES, Comisión Presidencial de seguimiento para la inversión pública e ISDEM. En efecto, luego de baber trabajado intensamente lograron cumplir con este objetivo. El documento parte de unas consideraciones muy generales sobre los desequilibrios territoriales, las desigualdades sociales, políticas y económicas que aquejan al país. Luego plantean los obstáculos que deberán superarse para lograr el desarrollo local. Dichos obstáculos se desglosan en ocho dimensiones: Político-administrativa y territorial; Institucional y legal; Participación y representación de los ciuda- 
La estrategia plantea nueve elementos estratégicos que se basa en el concepto de desarrollo local para superar dichos obstáculos. Éstos son los siguientes: El equilibrio en el territorio, el desarrollo y uso de la diversidad social y ecológica, el desarrollo bumano sostenible, globalización y localización, el desarrollo local, pertenencia e inclusión social, el desarrollo de la capacidad de concertación, el desarrollo de las capacidades locales, fortalecimiento de la participación e incidencia de lo local y el reconocimiento del municipio como unidad básica del Estado. Inmediatamente después, formula los objetivos generales $y$ especificos, los principios básicos y por último los componentes en cuatro áreas: Reorganización del marco institucional; Financiamiento para el desarrollo local; Desarrollo socioeconómico y Desarrollo ambiental.

La ENDL tuvo su momento de auge con la participación y concertación de diferentes actores, pero una vez el ejecutivo aprobó el documento en lugar de implementarlo, se ba pasado a un momento de ambigüedades $y$ de retrocesos, basta el punto de que el grupo consultivo al parecer, ha entrado en la fase de agotamiento (Umaña, 2002:47).

Sin la menor duda, está claro que, para un buen número de actores nacionales y locales, la pertinencia de la ENDL está fuera de discusión. Según sus planteamientos, el Desarrollo Local (DL) es más que un modelo que está de moda: constituye una alternativa real para mejorar la calidad de vida de la población, fortalecer la democracia, favorecer la gobernabilidad y dinamizar el crecimiento $y$ el desarrollo desde una perspectiva fundamentalmente bumana $y$ estratégicamente sostenible. Sin embargo, estas posturas, en diversos grados se quedan en el nivel del discurso, es decir del deber ser y adolecen de planteamientos factibles de operativización con estrategias y recursos para llevarlo a la práctica en el tiempo.

Para que el desarrollo local sea posible en El Salvador, hay que profundizar primero en el análisis del conjunto de obstáculos es- 
tructurales y coyunturales en el ámbito económico, politico, social, ambiental $e$ institucional que impiden o limitan la ejecución de esta estrategia. Lo contrario, lo que ya está provocando es la conformación de algunos enclaves de $D L$, más o menos exitosos $y$ el espejismo de que con estos esfuerzos se están solucionando los problemas estructurales en el contexto local.

La ENDL, por otra parte, no deja claro el tratamiento diferenciado de cada uno de los componentes que articula la propuesta. Sin perder de vista la visión integral que el documento busca en sus planteamientos, lo cierto es que no le da la centralidad que merece el Desarrollo Económico Local (DEL), como eje dinamizador de la estrategia.

En el DEL está una de las claves para que los otros componentes de la ENDL vayan provocando cambios estructurales en el territorio. La visión territorial del DEL puede contribuir a dinamizar la innovación y la calidad productiva y empresarial a través del fomento y desarrollo de las MIPYMES. Por otra parte, posibilitaría la movilización del potencial endógeno y la optimización de los recursos tanto locales como externos, lo que a su vez, fortalecería a los actores locales en su rol de agentes de desarrollo, siempre y cuando logren institucionalizar los espacios para la organización y funcionamiento de las agencias de desarrollo local $(A D L)$.

El DEL, en este sentido, demanda de un conjunto de acciones politico-administrativas que garantice su viabilidad y sostenibilidad. Una de estas acciones tiene necesariamente que ser la descentralización del Estado. Sin el traspaso de recursos y competencias a entidades intermedias y locales no podrá implementarse la ENDL. La gestión local del desarrollo demanda actores sociales fuertes, con los recursos minimos necesarios y las competencias claramente definidas para institucionalizar procesos. No obstante, en términos politicos la descentralización enfrenta grandes escollos. El pais tiene una histórica tradición presidencialista y centralista. El órgano ejecutivo siempre ba manejado grandes cuotas de poder $y$ desde 
estas ha intentado garantizar la gobernabilidad, por lo menos en cuanto a politica económica se refiere. Trasladar competencias y recursos implica desmonopolizar el ejercicio del poder y la toma de decisiones en cuanto a las políticas públicas y en cuento a la gobernabilidad. Sin embargo, el partido oficial ha sido renuente a este cambio, en su lugar, le ba apostado a la desconcentración, amén que, con esta estrategia de modernización, el partido gobernante sigue teniendo el poder necesario para garantizar la gobernabilidad en clave nacional.

Por otra parte, la falta de una instancia a nivel político-administrativo alimenta el argumento según el cual descentralizar recursos y competencias a los 262 municipios es inviable y que la medicina podría ser peor que la enfermedad. El cuestionamiento del gobierno central es que la mayoría de los gobiernos municipales no tienen la capacidad y el capital bumano y social necesarios para asumir $y$ administrar los recursos y competencias descentralizadas.

Por razones políticas e ideológicas es obvio que el actual gobierno central exagera su postura para justificar su reticencia a la descentralización. No obstante, existen serios problemas que bay que abordar para garantizar que la descentralización este en función del desarrollo. A escala estructural, la división política administrativa municipal constituye un serio obstáculo para transformar a los gobiernos municipales en agentes de desarrollo. Esto, por lo menos en dos sentidos, a saber: el primero de ellos tiene que ver con el marco jurídico legal. El carácter de ley secundaria que tienen las ordenanzas debilita la institucionalidad de los gobiernos municipales. Al final, lo que seguimos teniendo es la predominancia de las políticas públicas del gobierno central y la imposición de las lógicas sectoriales. El territorio municipal sigue siendo asumido como un espacio operativo y funcional tanto para el gobierno central como para las grandes empresas. En segundo lugar, dadas estas condiciones, los gobiernos municipales no podrán ser sostenibles financieramente para asumir su rol de agente de desarrollo y para poder financiar las funciones que le demanda su desempeño. Sin financiamiento propio, los gobiernos municipales dependerán siem-

\section{2}


pre de terceros y esta carencia seguirá impidiendo el fortalecimiento de su propio liderazgo. Para cambiar este panorama, se requiere de una reestructuración fiscal; no obstante, ello implica necesariamente la participación politica de la Asamblea Legislativa y del Poder Ejecutivo. Hasta el momento, existe una fuerte resistencia a reactivar el impuesto predial y a instituir nuevos impuestos municipales. Claramente, el rechazo a estas medidas tiene una intencionalidad politica que, de paso, cultiva el temor de otorgarle mayor autonomía política y financiera a los gobiernos locales.

Paradójicamente, y a pesar de estas grandes dificultades, los gobiernos municipales (en diferentes grados) ban ido acumulando capital social en torno al DL y al DEC. En efecto, muchos de estos gobiernos cuentan ya con su plan de ordenamiento territorial (POT) y han logrado plantear $y$ analizar las necesidades $y$ potencialidades de su propia base económica, en tanto municipio $y$ en cuanto microregión. De acuerdo a Albulquerque Llorens y Fernando Barreiro, estos pasos son una condición necesaria para articular una estrategia de DL. En estos documentos, las municipalidades que cuentan con él tienen información y análisis de las características de las infraestructuras básicas, de sus correspondientes demandas, así como de las condiciones socioeconómicas y demográficas de los territorios.

Sin embargo, la mayor parte de los municipios carecen de diagnósticos que den cuenta de la situación del mercado de trabajo local, de la base productiva y los tejidos empresariales existentes. Contar con esta información es clave para la elaboración de una estrategia de DL que identifique y ataque las debilidades del sistema productivo en cuanto formación ocupacional, comercialización, cooperación, entre otros.

En otras palabras, una estrategia de DEL demanda conocimiento científico sobre la base económica local y de su relación çon el marco político, jurídico, socioeconómico, tecnológico y competitivo vigente en el ámbito regional, nacional e internacional. En el ámbito político, la implementación de esta estrategia requiere que el 
gobierno municipal, fortalezca su liderazgo a fin de aumentar su capacidad de impulsar politicas que coadyuven en el mejoramiento de las redes de actores locales. Organizar una ADL sin tener como soporte estos componentes es perder tiempo y recursos. Una $A D L$ necesita contar con un sistema de información y asesoria; con una politica pública de inversión en soporte físico; con una política de promoción a la innovación tecnológica en la productividad y económica; con una politica de formación y desarrollo profesional de recursos humanos; con un gobierno municipal con la capacidad de gestión y por su puesto, con la voluntad política para reestructurar el sistema fiscal y el financiamiento, como un componente importante del proceso de descentralización.

Esta cuestión, a nivel teórico, hace énfasis en la importancia de ir desarrollando un entorno institucional, económico, social, politico y cultural apropiado. En la práctica, la realidad histórica e institucional de los municipios de El Salvador, señala que difícilmente cuentan con todos estos elementos; sin embargo, el carácter paulatino que debe tener una estrategia de DEL, alimentada de una visión de largo plazo puede contribuir a que los territorios a través de la gestión del gobierno local y del apoyo de las $A D L$ puedan crear las condiciones necesarias en relación con el desarrollo del potencial local desde los diferentes componentes teóricos antes expuesto.

En efecto, en el país se ba venido ganando terreno en cuanto a la necesidad de construir una visión de mediano y largo plazo en relación con el DEL. No obstante, aún faltan pulir las estrategias que logren articular el capital económico, el capital bumano, el capital social y por supuesto el capital natural en función de la sostenibilidad ambiental. En tal sentido, habrá que trabajar en función de tres grandes rubros. El primero de ellos, centrado en la articulación productiva y social de los territorios, a fin de aprovechar los recursos y las capacidades endógenas, así como las oportunidades externas. De lo que se trata aqui es de ir fortaleciendo la base económica local a través de procesos de innovación productiva $y$ comercial y por supuesto a través de los encadenamientos del 
tejido social y económico. El segundo tiene que girar en torno a la sustentabilidad ambiental en relación con la adecuación $y$ adaptación de tecnologias afines al medio ambiente y orientadas a aumentar la capacidad de ir atendiendo las necesidades básicas de la población. El tercer rubro, al igual que los anteriores es de suma importancia. La economía local está sujeta a los vaivenes de la económica regional, nacional e internacional. En tal sentido, la economía local debe demandarle al gobierno central políticas económicas que tomando en cuenta la economía de escalas, logre la estabilidad macroeconómica.

A manera de conclusión, se puede afirmar que, a través de las múltiples experiencias de un buen número de gobiernos municipales, se ha demostrado que estas entidades tienen la capacidad para jugar un rol importante como agente de desarrollo local, sin embargo, la falta de recursos y competencias provocan que estas iniciativas, en algunos casos concertadas con actores locales económicos y sociales, sigan siendo marginales.

El DEL demanda procesos de descentralización desde la administración central al gobierno municipal, pero también desde éste último hacia otras instancias o actores locales. Esta descentralización debe articular, desde la óptica de "abajo bacia arriba", las competencias y funciones de los diferentes actores, especialmente las que se refieren al ámbito político y técnico. Sin embargo, el DEL, como un conjunto de retos y estrategias de corto y mediano plazo, demanda de una adecuada articulación entre los procesos de ordenamiento territorial y los procesos de planificación estratégica de desarrollo local.

Desde este punto de vista, la ENLD no parte de un diagnóstico situacional profundo. Su contenido aborda políticamente aquellos temas relacionados con la descentralización, el marco legal y jurídico, las finanzas municipales, la inversión pública y el médio ambiente. Desde una concepción interdisciplinaria y técnica, esta ENLD tiene profundos vacios teórico-metodológicos. Dicho de otra manera, el desafío que actualmente tienen el gobierno central y los 
gobiernos locales es superar la polarización politica e ideológica, establecer mecanismos de interacción basados en la diálogo, negociación y concertación, es decir, debe montarse sobre una nueva base cultural. 